\title{
Strong Inhibition of Cholera Toxin B Subunit by Affordable, Polymer-Based Multivalent Inhibitors
}

\author{
Diksha Haksar, ${ }^{\dagger}$ Eyleen de Poel, ${ }^{\S}$ Linda Quarles van Ufford, ${ }^{\dagger}$ Sumati Bhatia, ${ }^{\ddagger}$ Rainer Haag, \\ Jeffrey Beekman, ${ }^{\S}$ and Roland J. Pieters ${ }^{*}+{ }^{\dagger}$ \\ ${ }^{\dagger}$ Department of Chemical Biology and Drug Discovery, Utrecht Institute for Pharmaceutical Sciences, Utrecht University, \\ Universiteitsweg 99, 3584 CG Utrecht, The Netherlands \\ ${ }^{\S}$ Department of Pediatric Pulmonology, Regenerative Medicine Center Utrecht, University Medical Centre Utrecht, Lundlaan 6, \\ 3508 GA Utrecht, The Netherlands \\ ${ }^{\ddagger}$ Institut für Chemie und Biochemie Organische Chemie, Freie Universität at Berlin, Takustr. 3, 14195 Berlin, Germany
}

Supporting Information

\begin{abstract}
Cholera is a potentially fatal bacterial infection that affects a large number of people in developing countries. It is caused by the cholera toxin ( $\mathrm{CT}$ ), an $\mathrm{AB}_{5}$ toxin secreted by Vibrio cholera. The toxin comprises a toxic A-subunit and a pentameric B-subunit that bind to the intestinal cell surface. Several monovalent and multivalent inhibitors of the toxin have been synthesized but are too complicated and expensive for practical use in developing countries. Meta-nitrophenyl $\alpha$ galactoside (MNPG) is a known promising ligand for CT, and here mono- and multivalent compounds based on MNPG were synthesized. We present the synthesis of MNPG in greatly improved yields and its use while linked to a multivalent scaffold. We used economical polymers as multivalent
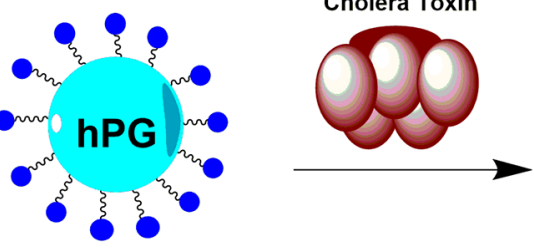

$=$ MNPG ligand scaffolds, namely, polyacrylamide, dextran, and hyperbranched polyglycerols (hPGs). Copper-catalyzed alkyne azide cycloaddition reaction (CuAAC) produced the inhibitors that were tested in an ELISA-type assay and an intestinal organoid swelling inhibition assay. The inhibitory properties varied widely depending on the type of polymer, and the most potent conjugates showed $\mathrm{IC}_{50}$ values in the nanomolar range.
\end{abstract}

C holera is a disease that affects a large number of people in developing countries because of limited access to safe drinking water and adequate sanitation. It is characterized by watery diarrhea which can rapidly be fatal when left untreated. ${ }^{1}$ The annual burden of cholera has been estimated at 1.3 to 4.0 million cases and 21000 to 143000 deaths worldwide. ${ }^{2}$ The recent cholera outbreak in Yemen has been called the world's worst cholera epidemic and has claimed 2200 lives in the year 2017 with more than a million suspected cases. ${ }^{3}$ Treatment for cholera involves the use of oral rehydration therapy and antibiotics. There are three oral cholera vaccines: Dukoral, Shanchol, and Euvichol-Plus/Euvichol which are WHO prequalified and widely used but not very effective for children under 5 years of age. ${ }^{4}$ Vaxchora has recently been approved by the USFDA as a vaccine for adults who travel to an area of active cholera transmission. ${ }^{5}$

Cholera is caused by the cholera toxin (CT) which is an $\mathrm{AB}_{5}$ toxin secreted by the Vibrio cholera bacterium. The core of the toxin consists of the A subunit which is responsible for the toxicity, surrounded by the pentameric B subunit. The B subunit enables the attachment of the toxin to GM1 ganglioside molecules on the intestinal cell surface which leads to endocytosis where the A subunit catalyzes $\mathrm{ADP}$ ribosylation of G-proteins leading to increased adenylate cyclase activity. ${ }^{6}$ This leads to increased intracellular cAMP, which results in a chloride outflow leading to water secretion and diarrhea. ${ }^{7}$ Therefore, preventing the entry of the toxin into the cell by blocking its attachment to the GM1 ganglioside is thought to be a good target for development of prophylactic drugs. ${ }^{8,9}$ The high-affinity binding interaction of GM1-CTB $\left(K_{\mathrm{d}}=43 \mathrm{nM}\right)$ has been demonstrated using isothermal titration calorimetry (ITC). ${ }^{10}$ A novel secondary binding site has been recently identified that binds to fucosylated molecules including fucosylated blood group antigens, although the binding is weaker with a $K_{d}$ of $1.4 \mathrm{mM}$ for the LeY-CTB binding. ${ }^{11,12}$ Another closely related $\mathrm{AB}_{5}$ toxin is heat-labile enterotoxin (LT1-B) that shares $80 \%$ sequence homology with CTB and causes traveler's diarrhea.'

GM1 mimics, as monovalent inhibitors of $\mathrm{CTB}^{13,14}$ and divalent ${ }^{15-18}$ inhibitors based on different scaffolds have been developed. Multivalent inhibitors based on different scaffolds

Received: December 18, 2018

Revised: January 9, 2019

Published: January 10, 2019 

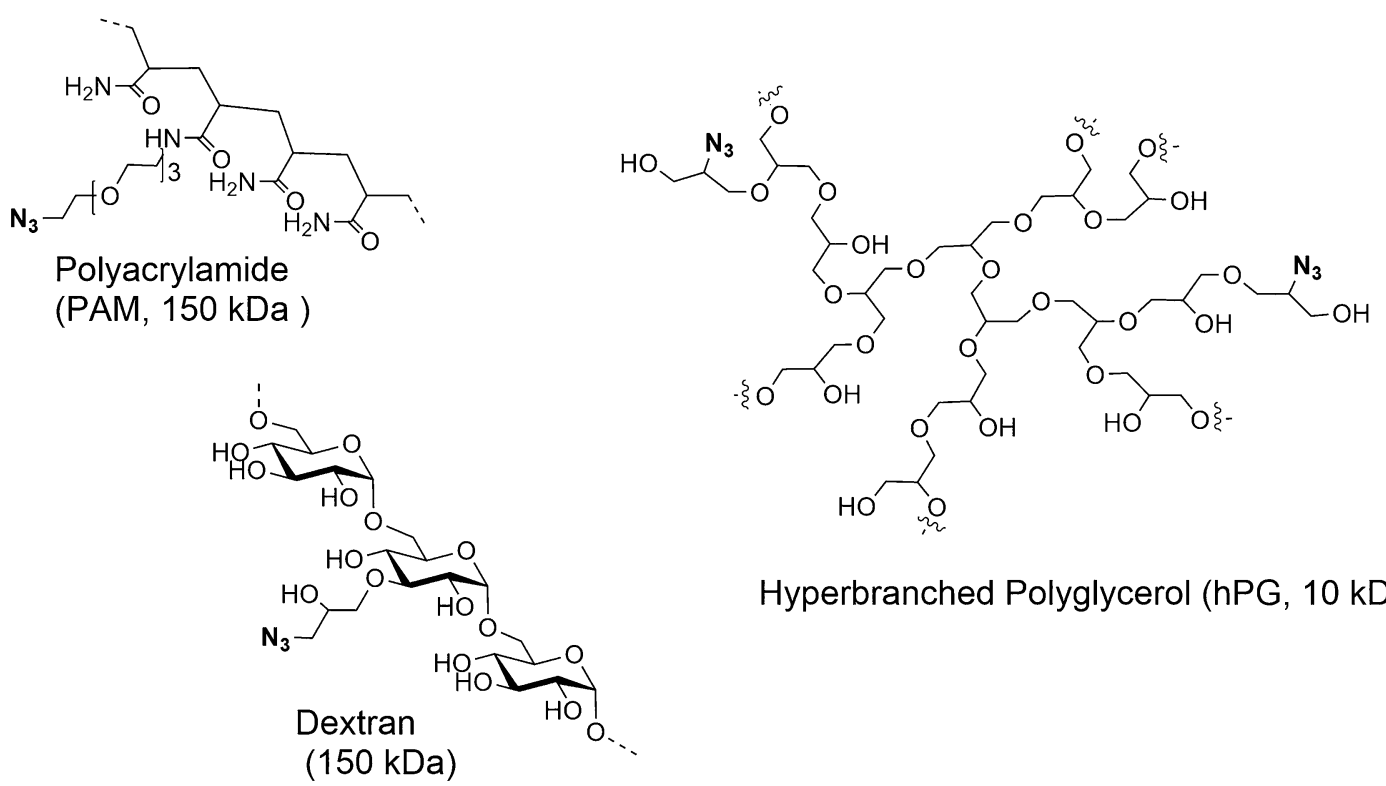

Hyperbranched Polyglycerol (hPG, 10 kDa)

Figure 1. Polymers used for the multivalent presentation of Cholera toxin ligands.

such as dendrimers, ${ }^{19}$ calix $[5]$ arene, $^{15}$ polymers, $^{20,21}$ and glycopeptides $^{22}$ have been synthesized. The most potent inhibitors are multivalent in nature and based on the GM1 oligosaccharide (GM1os). ${ }^{23-27}$ These systems are all very potent and inhibit in the nano- and picomolar range. Unfortunately, the structural complexity of GM1 and therefore the costs involved in preparing it does not make it an ideal candidate for drug development. The oligosaccharide of GM1 is very costly with hundreds of dollars for milligram amounts. Affordability is key, especially considering that the therapeutic needs to be repeatedly administered due to the natural flow of the intestinal tract, in order to maintain protection during epidemics. Thus, there is an urgent need for potent and economical inhibitors of CTB. To this end, researchers have conjugated galactose ligands to polymers and evaluated their potencies. ${ }^{28}$ One of the best examples is poly(L-glutamic)acid, and the inhibitor reached $\mathrm{IC}_{50} \mathrm{~s}$ in the $40-50 \mu \mathrm{M}$ range, a 600 fold enhancement over monovalent galactose. ${ }^{21}$ Similar results were reported with polyacrylamide linked galactoside, but a comparison with monovalent galactosides was not made. ${ }^{20}$ Tran et al. ${ }^{29}$ described a compound search of galactoside derivatives that were screened while linked to polyacrylamide and yielded potent conjugates, although the monovalent compound itself was of similar potency to MNPG used in our study (vide infra). Jones et al. ${ }^{30}$ used a similar approach. On the basis of these results, we aimed to make a polymeric CTB antagonist of sufficient potency that is readily made and consists of affordable components. Within these constraints, this should include an optimal monovalent ligand combined with an optimal polymeric pharmaceutically benign backbone. The word sufficient potency is based on the concentration of cholera toxin present during cholera attacks in the intestinal tract, which may reach close to $1 \mu \mathrm{M}$ of B-subunits. ${ }^{31,8}$ Submicromolar $K_{\mathrm{d}}$ 's are therefore sufficient while picomolar inhibitors provide little advantage, as they still need to be present in micromolar inhibitor concentration to neutralize all the toxin.

Meta-nitrophenyl $\alpha$-galactoside (MNPG) was the main candidate for our monovalent compound, which was discovered by Minke et al. almost two decades ago as a promising monovalent inhibitor in a screening assay where it exhibited a 100 -fold increase in potency over D-galactose. ${ }^{32}$ Its potency increases over galactose was thought to be entropydriven. This was explained by a new hydrogen bond formed with the nitro group liberating a conserved water molecule, in addition to increasing the surface of the ligand that can interact with the protein. ${ }^{32}$ Further optimization of MNPG did not yield satisfactory results. ${ }^{33,34}$ A multivalent version was potent when linked to a pentacyclen core $\left(\mathrm{IC}_{50} 6 \mathrm{nM}\right)$; however, the conjugate was not stable, ${ }^{35}$ and the result of a long and expensive synthesis. A major barrier was also the synthesis of MNPG and even more so for a version amenable to conjugation. Single-digit yields combined with the need for an enzyme to separate the anomeric mixtures precluded the use of MNPG for applications. ${ }^{33}$

In the present paper, we focused on the synthesis of MNPG and a version suitable for conjugation and subsequently presenting it in a polymeric multivalent system. For this purpose, we have used the linear polyacrylamide and dextran with periodic branching, typically less than $10 \%$, readily available and economical (Figure 1). The third polymer was considerably more branched: a hyperbranched polyglycerol (hPG) and known to be biocompatible and the $10 \mathrm{kDa}$ variant is known to have a more globular nanoparticle shape with a diameter of 5-6 nm, substituted or not. ${ }^{36-40}$ All three polymers were used as a scaffold by introducing azido functions and linking MNPG by copper-catalyzed alkyne azide cycloaddition (CuAAC) conjugation. The resulting glycopolymers were potent cholera toxin inhibitors, but the activity varied widely with the type of polymeric scaffold. Compounds were evaluated using an ELISA assay, but some compounds were also tested in our recently reported organoid assay. ${ }^{41}$ Traditionally, rabbit ileal loop assay has been used to study enterotoxins including CT. However, the assay is not widely used to evaluate CT inhibitors as it is extremely stressful to the animals, time-consuming, and not easy to standardize. The organoid assay overcomes these issues and could serve as a precursor to the animal model studies. 


\section{RESULTS}

Synthesis. A major limitation of the use of MNPG as a ligand suitable for conjugation, was its difficult, poorly described, and extremely low-yielding synthesis. ${ }^{33}$ In our hands, eventually an imidate-based, TfOH-catalyzed glycosylation proved to yield the desired $\alpha$ isomer with reasonable yields. 3-Hydroxy-5-nitrobenzoic acid was used as the starting point for the synthesis in which the acidic group was converted to a propargyl amide $\mathbf{2}$ (Scheme 1 ). Galactose imidate $\mathbf{1}^{42}$ was used as the glycosyl donor, and a glycosylation reaction was performed using triflic acid as the promoter wherein phenol (2), obtained from 3-hydroxy-5-nitrobenzoic acid, served as the acceptor. The glycosylation product (3) was obtained in $40-44 \%$. It was then deprotected to give the MNPG ligand 4

Scheme 1. Synthesis of MNPG and Derivatives ${ }^{a}$
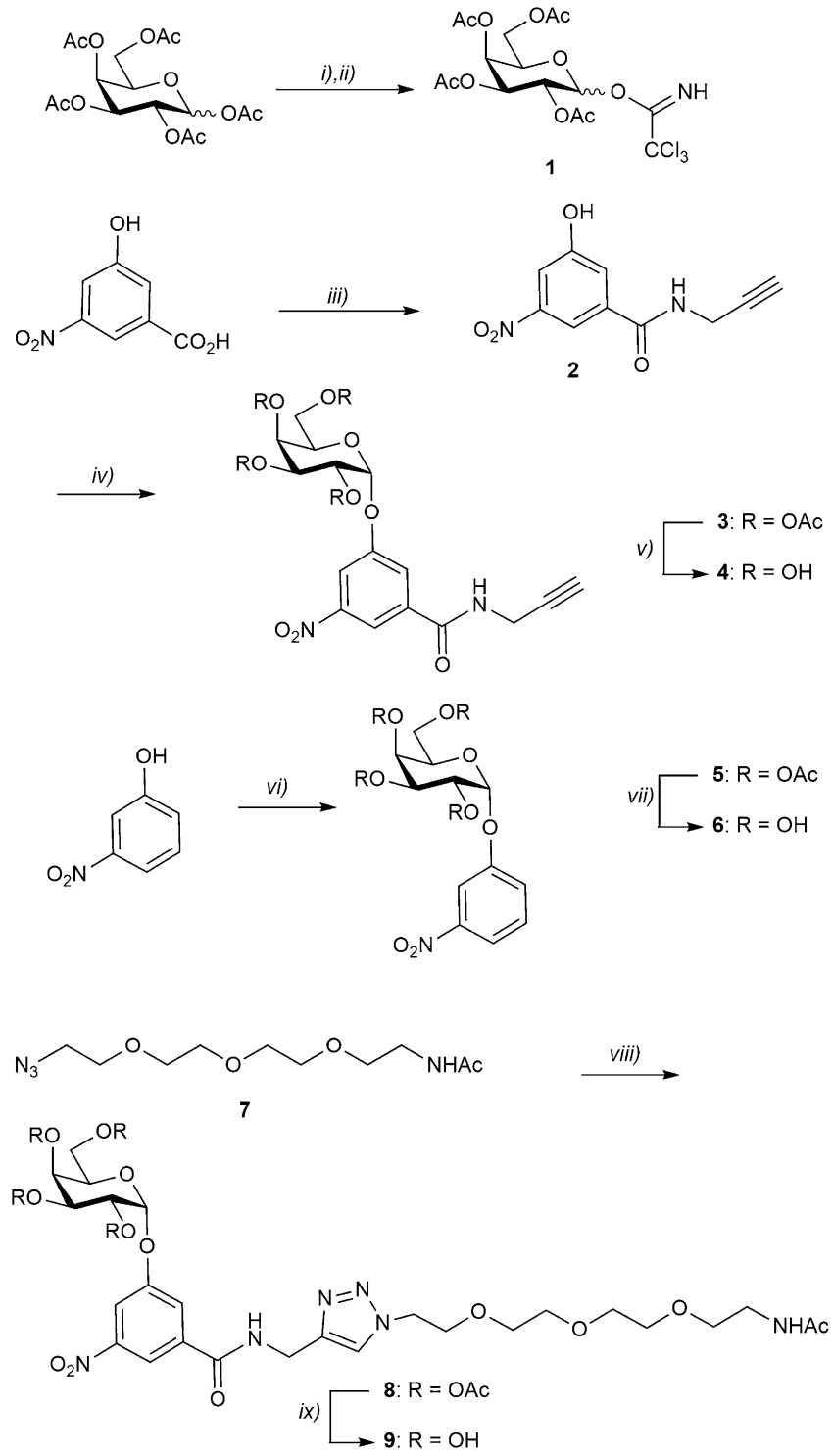

${ }^{a}$ Reagents and conditions: (i) $\mathrm{BnNH}_{2}, \mathrm{DMF}$, r.t., quantitative, (ii) Trichloroacetonitrile, $\mathrm{K}_{2} \mathrm{CO}_{3}, \mathrm{CH}_{2} \mathrm{Cl}_{2}, 96 \%$, (iii) Propargylamine, EDCI, DMAP, $76 \%$, (iv) 1 , TfOH, $-35{ }^{\circ} \mathrm{C}$ to r.t. $40-44 \%$, (v) $\mathrm{NaOH}, \mathrm{MeOH}, 85 \%$, (vi) 1, $\mathrm{TfOH},-35{ }^{\circ} \mathrm{C}$-r.t. $58 \%$, (vii) $\mathrm{NaOH}, \mathrm{MeOH}, 83 \%$, (viii) 3, $\mathrm{CuSO}_{4}, \mathrm{Na}$. ascorbate, microwave, $75 \%$, (ix) $\mathrm{NaOH}, \mathrm{MeOH}, 73 \%$. that was used for the "click" reaction with the different polymeric scaffolds. We have synthesized unsubstituted MNPG using 3-nitrophenol as the glycosyl acceptor and galactose imidate as the donor in the triflic-acid-promoted glycosylation to give the $\alpha$-isomer 5 in $58 \%$ yield, which was deprotected to give MNPG (6).

Besides compounds 4 and 6, a third MNPG-based and more soluble monovalent compound was synthesized using 11azido-3,6,9-trioxundecan-1-amine by first converting the amine to amide 7 and then conjugating it to 3 to give 8 which was deprotected to give 9. 11-Azido-3,6,9-trioxundecan-1-amine was also used for the conjugation of an azide moiety to polyacrylamide $(\mathrm{Mn}: 150 \mathrm{kDa})$ and dextran $(\mathrm{Mn}: 150 \mathrm{kDa})$ according to reported procedures ${ }^{43,29}$ to give polymers $\mathbf{1 0}$ and 11, respectively (Scheme 2 ). The incorporation of the azide group was confirmed by the appearance of the azide stretching peak at $2110 \mathrm{~cm}^{-1}$ in the infrared spectroscopy (IR) spectra. The molecular weights and the percent azide functionalization of 10 and 11 ( $1.7 \%$ and $0.6 \%$ respectively) were calculated by integrating relevant peaks in the proton NMR spectra. ${ }^{43} \mathrm{~A}$ shorter azide containing appendage was also used to functionalize dextran. ${ }^{44}$ To this end 1-azido-2,3-epoxypropane was used which was synthesized in two steps from epichlorohydrin (see Supporting Information). Polymer 12 was obtained with a $6 \%$ azide functionalization, as determined by proton NMR and was conjugated to the MNPG ligand 4 and prop-2-ynyl $\beta$-galactoside using CuAAC to give 15 and 17, respectively. The complete disappearance of the azide stretching peak in each of the reactions confirmed that all of the polymer azide was consumed (see Supporting Information). hPG (Mn: 10,000) with a $10 \%$ azide functionalization was prepared as before ${ }^{40}$ and used for conjugation to 4 to give glycopolymer 18.

Cholera Toxin Inhibition. The synthesized compounds were tested for their ability to inhibit the cholera toxin Bsubunit by making use of the well-established GM1-based ELISA assay. Galactose was used as a reference inhibitor and was the least potent molecule with an $\mathrm{IC}_{50}$ of $111 \mathrm{mM}$ (Table 1). Monovalent inhibitors MNPG (6) and its derivative 9 showed inhibition in the low millimolar range. MNPG emerged as the best monovalent ligand with a 58 -fold potency increase over galactose $\left(\mathrm{IC}_{50} 1.9 \mathrm{mM}\right)$, which is comparable to the reported enhancement values. Compound 9 showed 27fold potency gain over galactose $\left(\mathrm{IC}_{50}: 4 \mathrm{mM}\right)$. All of the multivalent compounds showed at least inhibition in the low micromoler range. Dextran-based compound 15 and hPGbased compound 18 emerged as the most potent with comparable $\mathrm{IC}_{50}$ values in the nanomolar range (390 and $530 \mathrm{nM}$, respectively). Dextran-MNPG conjugate 15 was more potent than the dextran-galactose conjugate 17 despite the same number of azides on the dextran thereby confirming the inhibitory potential of MNPG. Polyacrylamide-MNPG conjugate 13 and dextran conjugate 14 also showed significant inhibition ( $\mathrm{IC}_{50} \mathrm{~s}$ of 5.6 and $8.4 \mu \mathrm{M}$ ).

Besides the ELISA assay, the best multivalent glycopolymers $(13,15,18)$ along with all the monovalent compounds were evaluated for their inhibitory potential in our recently reported organoid assay. ${ }^{41}$ To apply the organoid assay, intestinal organoids $^{45}$ were stimulated dose dependently with cholera toxin to select a nonsaturating concentration for inhibitor testing while retaining maximal assay sensitivity (see Supporting Information). A concentration of $3 \mu \mathrm{g} / \mathrm{mL}$ of cholera toxin was required to induce sufficient swelling of these 
Scheme 2. Synthesis of MNPG- and Galactose-Based Polymers ${ }^{a}$
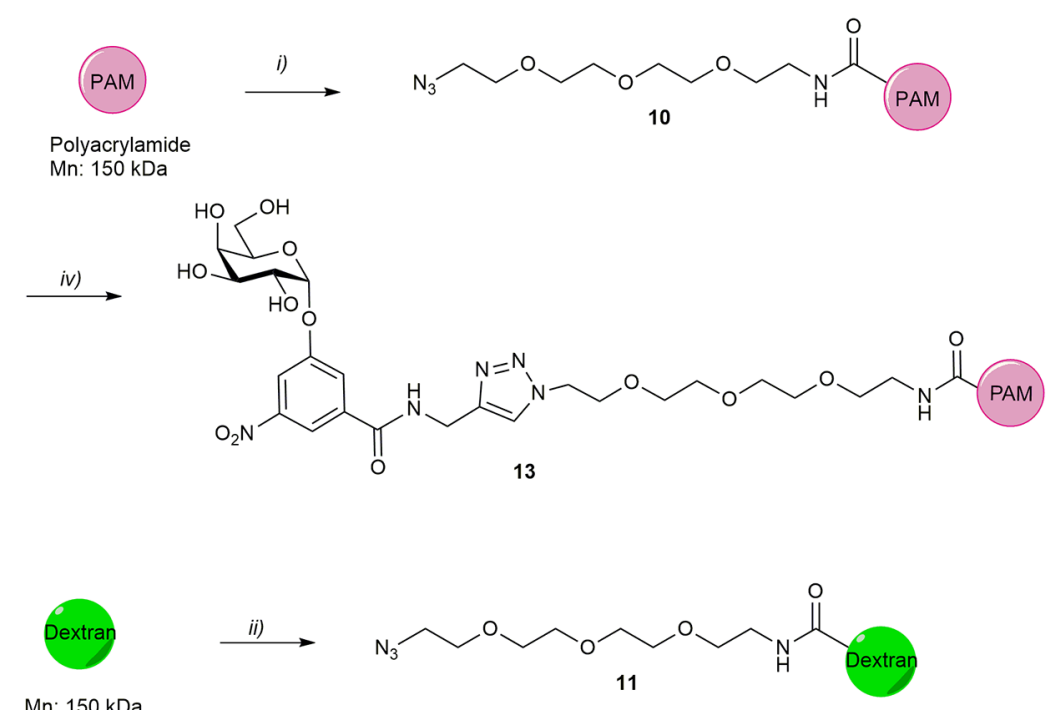

$\mathrm{Mn}: 150 \mathrm{kDa}$
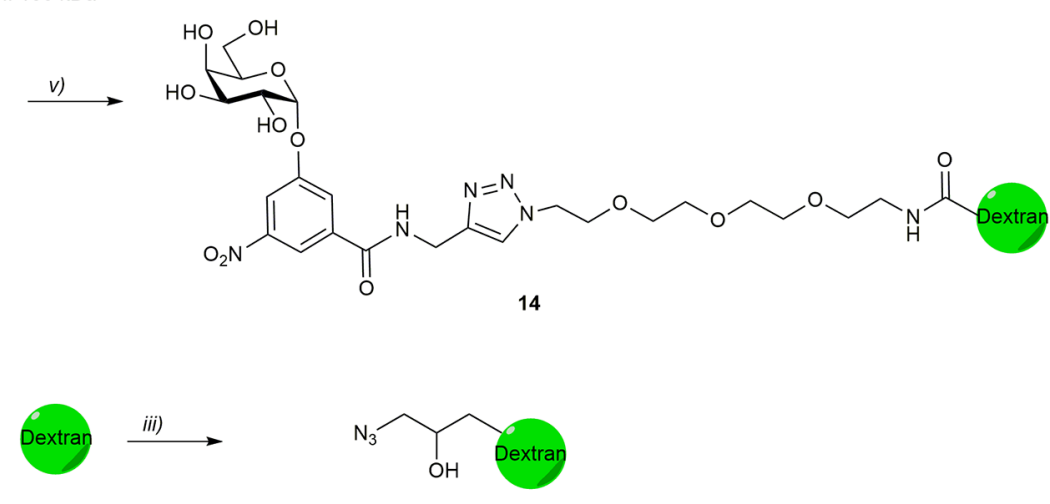

$\mathrm{Mn}: 150 \mathrm{kDa}$

12

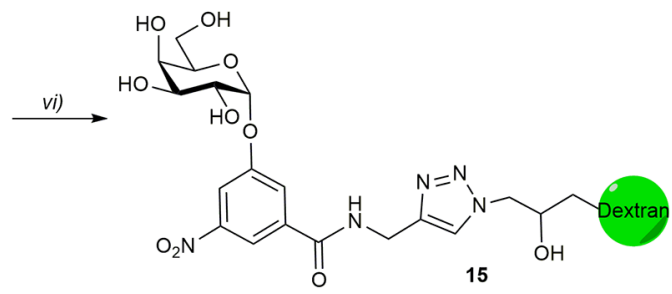
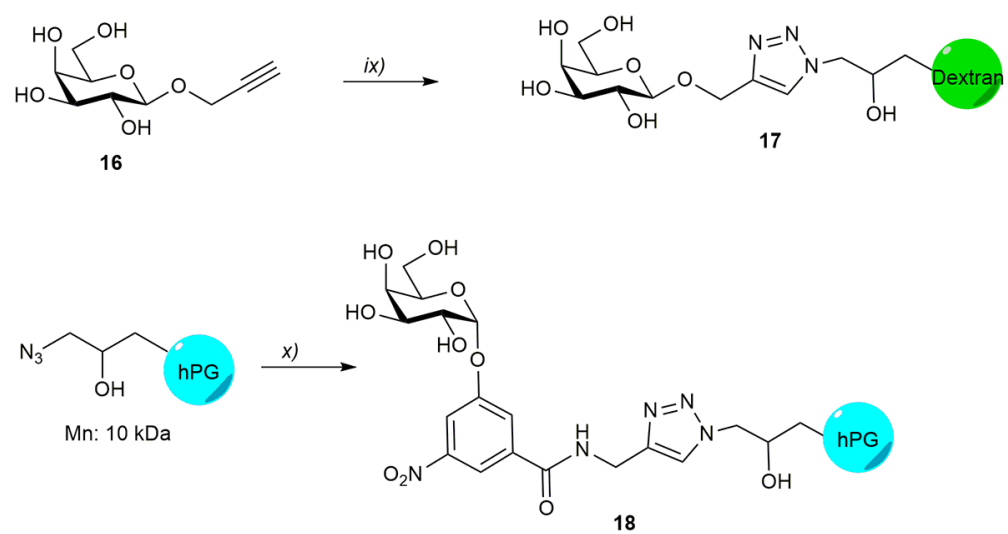

${ }^{a}$ (i) 11-Azido-3,6,9-trioxaundecan-1-amine, $80{ }^{\circ} \mathrm{C}, 60 \mathrm{~min}, 95 \%$, (ii) 11-Azido-3,6,9-trioxaundecan-1-amine, CDI, DMAP, DMSO, r.t., 48h, (iii) a) iPrOH, AcOH, $\mathrm{NaN}_{3}$, Epichlorohydrin, $5 \mathrm{M} \mathrm{NaOH}$, b) $5 \mathrm{M} \mathrm{NaOH}$, (iv) 4,CuSO${ }_{4}, \mathrm{Na}$. ascorbate, $100{ }^{\circ} \mathrm{C}, 78 \%$, (v) 4,CuSO, $\mathrm{Na}^{\circ}$ ascorbate, $100{ }^{\circ} \mathrm{C}$, $83 \%$, vi) $4, \mathrm{CuSO}_{4}$, Na. ascorbate, $100{ }^{\circ} \mathrm{C}, 51-58 \%$, ix) $12, \mathrm{CuSO}_{4}$, Na. ascorbate, $\left.100{ }^{\circ} \mathrm{C}, 35 \%, \mathrm{x}\right) 4, \mathrm{CuSO}_{4}, \mathrm{Na}$. ascorbate, $100{ }^{\circ} \mathrm{C}, 62 \%$. 
Table 1. Results of Inhibition by Multivalent Carbohydrates in CTB-HRP ELISA Assay ${ }^{a}$

\begin{tabular}{|c|c|c|c|c|c|c|c|}
\hline entry & construct & ligand & valency (\% functionalization of polymer) & $\mathrm{IC}_{50}(\mu \mathrm{M})$ & rel. pot. $^{b}$ & rel. pot. per sugar ${ }^{c}$ & $\mathrm{IC}_{50}(\mu \mathrm{g} / \mathrm{mL})$ \\
\hline 1 & galactose & gal & 1 & $111500 \pm 10000$ & 1 & 1 & 20087 \\
\hline 2 & 6 & MNPG & 1 & $1907 \pm 420$ & 58 & 58 & 574 \\
\hline 3 & 9 & MNPG & 1 & $4095 \pm 230$ & 27 & 27 & 2628 \\
\hline 4 & 17 & gal & $55(6 \%)$ & $6.6 \pm 1$ & 16870 & 304 & 1108 \\
\hline 5 & 13 & MNPG & $36(1.7 \%)$ & $5.6 \pm 0.5$ & 731 & 20 & 961 \\
\hline 6 & 15 & MNPG & $55(6 \%)$ & $0.39 \pm 1$ & 10500 & 191 & 69 \\
\hline 7 & 14 & MNPG & $6(0.6 \%)$ & $8.4 \pm 1$ & 488 & 81 & 1299 \\
\hline 8 & 18 & MNPG & $13(10 \%)$ & $0.53 \pm 2$ & 7726 & 594 & 8 \\
\hline
\end{tabular}

${ }^{a}$ Determined in an ELISA-like assay with $\mathrm{CTB}_{5}-\mathrm{HRP}(40 \mathrm{ng} / \mathrm{mL})$ and wells coated with GM1. ${ }^{b}$ Relative to the potency of galactose for 6 , 9, and 17, and to 9 for the rest. ${ }^{c}$ Relative potency divided by the valency.

Table 2. Results of Inhibition of CT-Induced Swelling of Intestinal Organoids by Multivalent Carbohydrates ${ }^{a}$

\begin{tabular}{|c|c|c|c|c|c|c|c|}
\hline entry & construct & ligand & valency (\% functionalization of polymer) & $\mathrm{IC}_{50}(\mu \mathrm{M})$ & rel. pot. ${ }^{b}$ & rel. pot. per sugar ${ }^{c}$ & $\mathrm{IC}_{50}(\mu \mathrm{g} / \mathrm{mL})$ \\
\hline 1 & galactose & gal & 1 & $100000 \pm 10000$ & 1 & 1 & 18015 \\
\hline 2 & 6 & MNPG & 1 & $13380 \pm 1844$ & 7 & 7 & 4269 \\
\hline 3 & 9 & MNPG & 1 & $9993 \pm 1100$ & 10 & 10 & 6413 \\
\hline 4 & 13 & MNPG & $36(1.7 \%)$ & $15.5 \pm 5$ & 644 & 18 & 2583 \\
\hline 5 & 15 & MNPG & $55(6 \%)$ & $12 \pm 4$ & 832 & 15 & 2121 \\
\hline 6 & 18 & MNPG & $13(10 \%)$ & $6.9 \pm 2$ & 1448 & 111 & 110 \\
\hline
\end{tabular}

${ }^{a}$ Determined in an assay observing the swelling of intestinal organoids by CT as a function of inhibitor concentration. ${ }^{b}$ Relative to the potency of galactose for $\mathbf{6}$ and $\mathbf{9}$, and to 9 for the rest. ${ }^{c}$ Relative potency divided by the valency.

donor derived organoids, which is 30 times higher than was needed for previously used organoids derived from a different donor. ${ }^{41}$ We next assessed dose-dependent inhibition of cholera toxin-mediated swelling of the inhibitors for binding cholera toxin B subunit. Galactose was measured as a reference inhibitor. Organoids were stimulated with cholera toxin, with or without inhibitors. We found that all the polymer-based compounds were potent inhibitors of cholera toxin-induced swelling, with $\mathrm{IC}_{50}$ values in the low micromolar range Table 2). hPG-based inhibitor (18) was the most potent $(6.9 \mu \mathrm{M})$ with 13 and 15 showing comparable inhibition $\left(\mathrm{IC}_{50}\right.$ of 15 and $12 \mu \mathrm{M})$. Galactose was the least potent ( $\mathrm{IC}_{50}$ of $100 \mathrm{mM}$ ) with MNPG 6 and 9 inhibiting in the low millimolar concentration $\left(\mathrm{IC}_{50}\right.$ of 13 and $9.9 \mathrm{mM}$ respectively).

\section{DISCUSSION}

We have synthesized and evaluated glycoconjugates as inhibitors of the cholera toxin. Our previous dendrimers containing GMlos were very potent, but not economically practical for application. ${ }^{46,41}$ To put this into perspective, the GM1 sugar that was used for the synthesis currently (2018) costs ca. 400 USD per miligram, whereas the polymers used by us only cost a fraction, that is, just a dollar or so per gram, which is also the case for 3-hydroxy-5-nitrobenzoic acid, while bulk prices are much lower. For the first time, we described a step-by-step synthesis of MNPG, whereby it can be easily synthesized and purified in good quantities. The fact that only the $\alpha$-isomer of MNPG and derivatives was obtained may be due to the anomeric effect providing enhanced stability for the $\alpha$-isomer caused by the electron-withdrawing nitrophenyl group. TfOH likely catalyzes the anomerization to the $\alpha$ isomer even if the $\beta$-isomer was formed also. Similar observations were made previously. ${ }^{47}$ We also developed a reaction strategy to incorporate it in a multivalent system by synthesizing compound 4 . Following this, we have successfully incorporated it into the polymeric scaffolds (i.e., polyacrylamide, dextran, and hPG) of varying azide functionalization for the synthesis of the final multivalent compounds. The inhibitory potential of the synthesized compounds was evaluated using the GM1 ELISA protocol. Additionally, an intestinal organoid swelling inhibition assay was performed which is a more biorelevant in vitro assay to confirm the inhibitory potential of the synthesized compounds. The most important measure for the potency enhancement imparted by the scaffold on which the ligands are presented is the potency per ligand. If a divalent ligand is twice as potent compared to the monovalent ligand it essentially provides no benefit, the relative potency per ligand is 1 . The highest number observed here is 594-fold for 18. This is a big number and clearly shows the large benefit of the hPG nanoparticle/polymer. The second best was galactose based-dextran conjugate 17 with a 304-fold potency enhancement over galactose. The same scaffold also yielded a high potency enhancement for MNPG linked to the same scaffold, but here the number was 191-fold per sugar. Interestingly, the most effective polymeric backbone seems to be the hPG especially when expressing its activity in terms of $\mu \mathrm{g} / \mathrm{mL}$ of the whole polymeric construct. Its geometry is considered a nanoparticle with a ca. 5-6 nm diameter, ${ }^{40}$ which matches the toxin diameter size $(6-7 \mathrm{~nm}$ diameter) quite well. This is a feature that was recently shown to be favorable and of importance for strong inhibition, based on computational studies. ${ }^{48}$ Our previous multivalent dendritic nonpolymeric inhibitors, including a pentavalent one, were shown to aggregate the toxin by analytical ultracentrifuge measurements, which may have contributed to their potency. ${ }^{49,50}$ One-on-one complexes have also been reported by DLS for a well-defined $\mathrm{CTB}_{5}$-based inhibitor, ${ }^{23}$ as well as $2: 1$ complexes for a decavalent system. ${ }^{51}$ On this basis, it is likely that the polymeric and nanoparticle inhibitors described here, which are of higher valency than our mentioned dendritic inhibitors, 
also bind to multiple toxins and induce aggregation that way. We here observed a distinct advantage of the nanoparticle hPG as the ligand scaffold over the linear polyacrylamide and the sporadically cross-linked dextran. A possible explanation is that a high number of ligands in a small area is beneficial as they can occupy several of the toxin binding sites simultaneously. The hPG also had the highest ligand density of $10 \%$, and for dextran, the higher ligand density of $\mathbf{1 5}$ was beneficial in comparison to the 10 times lower functionalized 14. The hPG seemed to be the most potent due to a combination of the particle shape of suitable size and a relatively high functionalization. Even though the polyacrylamide and dextran backbones were previously shown ${ }^{29}$ to be highly effective ligand scaffold, the hPG is clearly superior. This is particularly clear when expressing the potency in terms of $\mu \mathrm{g} / \mathrm{mL}$, where the weight of the polymer and the ligand density also play a role.

The cholera toxin inhibition observed here is of sufficient practical potency, which should be able to neutralize the up to micromolar quantities of the toxin B-subunits present in an active infection by repeated administration. The polyacrylamide backbone was the least effective in our study, and is suspect with respect to toxicity. ${ }^{52}$ The dextran polymeric backbone is biodegradable, which is considered an advantage for our application, ${ }^{29}$ and has also been used by others in the intestinal tract. ${ }^{53}$ The hPG nanoparticles have been studied in detail for their behavior in biological systems and found to be nontoxic. $^{54}$

\section{CONCLUSION}

We have prepared a new potent conjugate between MNPG and the pharmaceutically benign hPG nanoparticle platform. The new synthesis makes MNPG readily accessible, and the conjugate showed good potency against the cholera toxin Bsubunit in two assays, with potential as a prophylactic drug in cholera epidemics.

\section{ASSOCIATED CONTENT}

\section{S Supporting Information}

The Supporting Information is available free of charge on the ACS Publications website at DOI: 10.1021/acs.bioconjchem.8b00902.

Experimental details, NMR, inhibition curves for ELISA assay, inhibition curves for organoid assay, and IR spectra (PDF)

\section{AUTHOR INFORMATION}

\section{Corresponding Author}

*E-mail: R.J.Pieters@uu.nl; Phone: +31620293387.

\section{ORCID}

Roland J. Pieters: 0000-0003-4723-3584

\section{Notes}

The authors declare no competing financial interest.

\section{REFERENCES}

(1) World Health Organization. https://www.who.int/en/newsroom/fact-sheets/detail/cholera (accessed Jan. 9, 2019).

(2) Ali, M., Nelson, A. R., Lopez, A. L., and Sack, D. A. (2015) Updated global burden of cholera in endemic countries. PLoS Neglected Trop. Dis. 9, No. e0003832.
(3) WHO Annual Report 2017 Yemen; WHO Regional Office for the Eastern Mediterranean: Cairo, 2018. Cairo. License: CC BYNC-SA 3.0 IGO.

(4) Chowdhury, F. R., Nur, Z., Hassan, N., von Seidlein, L., and Dunachie, S. (2017) Pandemics, pathogenicity and changing molecular epidemiology of cholera in the era of global warming. Ann. Clin. Microbiol. Antimicrob. 16, 10.

(5) Mosley, J. F., Smith, L. L., Brantley, P., Locke, D., Como, M., and Como, M. (2017) Vaxchora: The First FDA-Approved Cholera Vaccination in the United States. P T 42, 638-640.

(6) Turnbull, W. B., and Hayes, E. D. (2011) Monovalent and Multivalent Inhibitors of Bacterial Toxins. In Synthesis and Biological Applications of Glycoconjugates (Renaudet, O., and Spinelli, N., Eds.) pp 78-91, Bentham Science Publishers.

(7) Baldauf, K. J., Royal, J. M., Hamorsky, K. T., and Matoba, N. (2015) Cholera toxin B: one subunit with many pharmaceutical applications. Toxins 7, 974-96.

(8) Zuilhof, H. (2016) Fighting Cholera One-on-One: The Development and E ffi cacy of Multivalent Cholera-Toxin-Binding Molecules. Acc. Chem. Res. 49, 274-285.

(9) Kumar, V., and Turnbull, W. B. (2018) Carbohydrate inhibitors of cholera toxin. Beilstein J. Org. Chem. 14, 484-498.

(10) Turnbull, W. B., Precious, B. L., and Homans, S. W. (2004) Dissecting the Cholera Toxin-Ganglioside GM1 Interaction by Isothermal Titration Calorimetry. J. Am. Chem. Soc. 126, 1047-1054.

(11) Wands, A. M., Cervin, J., Huang, H., Zhang, Y., Youn, G., Brautigam, C. A., Matson Dzebo, M., Björklund, P., Wallenius, V., Bright, D. K., Bennett, C. S., Wittung-Stafshede, P., Sampson, N. S., Yrlid, U., and Kohler, J. J. (2018) Fucosylated Molecules Competitively Interfere with Cholera Toxin Binding to Host Cells. ACS Infect. Dis. 4, 758-770.

(12) Wands, A. M., Fujita, A., McCombs, J. E., Cervin, J., Dedic, B., Rodriguez, A. C., Nischan, N., Bond, M. R., Mettlen, M., Trudgian, D. C., Lemoff, A., Quiding-Järbrink, M., Gustavsson, B., Steentoft, C., Clausen, H., Mirzaei, H., Teneberg, S., Yrlid, U., and Kohler, J. J. (2015) Fucosylation and protein glycosylation create functional receptors for cholera toxin. eLife 4, 1-38.

(13) Bernardi, A., Checchia, A., Brocca, P., Sonnino, S., and Zuccotto, F. (1999) Sugar mimics: An artificial receptor for cholera toxin. J. Am. Chem. Soc. 121, 2032-2036.

(14) Bernardi, A., Carrettoni, L., Ciponte, A. G., Monti, D., and Sonnino, S. (2000) Second Generation Mimics of Ganglioside GM1 as Arti ${ }^{\circledR}$ cial Receptors for Cholera Toxin: Replacement of the Sialic Acid Moiety. Bioorg. Med. Chem. Lett. 10, 2197-2200.

(15) Arosio, D., Fontanella, M., Baldini, L., Mauri, L., Bernardi, A., Casnati, A., Sansone, F., and Ungaro, R. (2005) A Synthetic Divalent Cholera Toxin Glycocalix[4]arene Ligand Having Higher Affinity than Natural GM1 Oligosaccharide Scheme 1. Synthesis of the Divalent Ligand 1. J. Am. Chem. Soc. 127, 3660-3661.

(16) Cheshev, P., Morelli, L., Marchesi, M., Podlipnik, Č. Bergström, M., and Bernardi, A. (2010) Synthesis and affinity evaluation of a small library of bidentate cholera toxin ligands: Towards nonhydrolyzable ganglioside mimics. Chem. - Eur. J. 16, 1951-1967.

(17) Leaver, D. J., Hughes, A. B., Dawson, R. M., Postma, A., Malic, N., and Polyzos, A. (2014) Synthesis of RAFT polymers as bivalent inhibitors of cholera toxin. RSC Adv. 4, 14868-14871.

(18) Leaver, D. J., Dawson, R. M., White, J. M., Polyzos, A., and Hughes, A. B. (2011) Synthesis of 1,2,3-triazole linked galactopyranosides and evaluation of cholera toxin inhibition. Org. Biomol. Chem. 9, 8465.

(19) Arosio, D., Vrasidas, I., Valentini, P., Liskamp, R. M. J., Pieters, R. J., and Bernardi, A. (2004) Synthesis and cholera toxin binding properties of multivalent GM1 mimics. Org. Biomol. Chem. 2, 21132124.

(20) Richards, S.-J., Jones, M. W., Hunaban, M., Haddleton, D. M., and Gibson, M. I. (2012) Probing bacterial-toxin inhibition with synthetic glycopolymers prepared by tandem post-polymerization 
modification: role of linker length and carbohydrate density. Angew. Chem., Int. Ed. 51, 7812-6.

(21) Polizzotti, B. D., and Kiick, K. L. (2006) Effects of polymer structure on the inhibition of cholera toxin by linear polypeptidebased glycopolymers. Biomacromolecules 7, 483-490.

(22) Kumar, V., Yadav, N., and Kartha, K. P. R. (2016) Synthetic multivalent ligands for cholera \& cholera-like toxins: Protected cyclic neoglycopeptides. Carbohydr. Res. 431, 47-55.

(23) Branson, T. R., McAllister, T. E., Garcia-Hartjes, J., Fascione, M. A., Ross, J. F., Warriner, S. L., Wennekes, T., Zuilhof, H., and Turnbull, W. B. (2014) A protein-based pentavalent inhibitor of the cholera toxin B-subunit. Angew. Chem., Int. Ed. 53, 8323-7.

(24) Fu, O., Pukin, A. V., van Ufford, H. C. Q., Branson, T. R., Thies-Weesie, D. M. E., Turnbull, W. B., Visser, G. M., and Pieters, R. J. (2015) Tetra- versus Pentavalent Inhibitors of Cholera Toxin. ChemistryOpen 4, 471-477.

(25) Garcia-Hartjes, J., Bernardi, S., Weijers, C. A. G. M., Wennekes, T., Gilbert, M., Sansone, F., Casnati, A., and Zuilhof, H. (2013) Picomolar inhibition of cholera toxin by a pentavalent ganglioside GM1os-calix[5] arene. Org. Biomol. Chem. 11, 4340-4349.

(26) Pukin, A. V., Branderhorst, H. M., Sisu, C., Weijers, C. A. G. M., Gilbert, M., Liskamp, R. M. J., Visser, G. M., Zuilhof, H., and Pieters, R. J. (2007) Strong Inhibition of Cholera Toxin by Multivalent GM1 Derivatives. ChemBioChem 8, 1500-1503.

(27) Das, S., Angsantikul, P., Le, C., Bao, D., Miyamoto, Y., Gao, W., Zhang, L., and Eckmann, L. (2018) Neutralization of cholera toxin with nanoparticle decoys for treatment of cholera. PLoS Neglected Trop. Dis. 12, e0006266.

(28) Weisman, A., Chou, B., O’Brien, J., and Shea, K. J. (2015) Polymer antidotes for toxin sequestration. Adv. Drug Delivery Rev. 90, $81-100$.

(29) Tran, H.-A., Kitov, P. I., Paszkiewicz, E., Sadowska, J. M., and Bundle, D. R. (2011) Multifunctional multivalency: a focused library of polymeric cholera toxin antagonists. Org. Biomol. Chem. 9, 365871.

(30) Jones, M. W., Otten, L., Richards, S. J., Lowery, R., Phillips, D. J., Haddleton, D. M., and Gibson, M. I. (2014) Glycopolymers with secondary binding motifs mimic glycan branching and display bacterial lectin selectivity in addition to affinity. Chem. Sci. 5, $1611-1616$.

(31) Turnbull, P. C. B., Lee, J. V., Miliotis, M. D., Still, C. S., Isaacson, M., and Ahmad, Q. S. (1985) In Vitro and In Vivo Cholera Toxin Production by Classical and El Tor Isolates of Vibrio cholerae. J. Clin. Microbiol. 21, 884-890.

(32) Minke, W. E., Roach, C., Hol, W. G. J., and Verlinde, C. L. M. J. (1999) Structure-based exploration of the ganglioside GM1 binding sites of Escherichia coli heat-labile enterotoxin and cholera toxin for the discovery of receptor antagonists. Biochemistry 38, 5684-5692.

(33) Pickens, J. C., Merritt, E. A., Ahn, M., Verlinde, C. L. M. J., Hol, W. G. J., and Fan, E. (2002) Anchor-based design of improved cholera toxin and E. coli heat-labile enterotoxin receptor binding antagonists that display multiple binding modes. Chem. Biol. 9, 21524.

(34) Mitchell, D. D., Pickens, J. C., Korotkov, K., Fan, E., and Hol, W. G. J. (2004) 3,5-Substituted phenyl galactosides as leads in designing effective cholera toxin antagonists: Synthesis and crystallographic studies. Bioorg. Med. Chem. 12, 907-920.

(35) Zhang, Z., Pickens, J. C., Hol, W. G. J., and Fan, E. (2004) Solution- and Solid-Phase Syntheses of Guanidine-Bridged, WaterSoluble Linkers for Multivalent Ligand Design. Org. Lett. 6, 13771380.

(36) Papp, I., Dernedde, J., Enders, S., and Haag, R. (2008) Modular synthesis of multivalent glycoarchitectures and their unique selectin binding behavior. Chem. Commun., 5851 .

(37) Calderón, M., Quadir, M. A., Sharma, S. K., and Haag, R. (2010) Dendritic polyglycerols for biomedical applications. Adv. Mater. 22, 190-218.
(38) Haag, R., Sunder, A., and Stumbé, J. F. (2000) An approach to glycerol dendrimers and pseudo-dendritic polyglycerols [6]. J. Am. Chem. Soc. 122, 2954-2955.

(39) Bhatia, S., Lauster, D., Bardua, M., Ludwig, K., AngiolettiUberti, S., Popp, N., Hoffmann, U., Paulus, F., Budt, M., Stadtmüller, M., Wolff, T., Hamann, A., Böttcher, C., Herrmann, A., and Haag, R. (2017) Linear polysialoside outperforms dendritic analogs for inhibition of influenza virus infection in vitro and in vivo. Biomaterials $138,22-34$.

(40) Sisson, A. L., Steinhilber, D., Rossow, T., Welker, P., Licha, K., and Haag, R. (2009) Biocompatible Functionalized Polyglycerol Microgels with Cell Penetrating Properties. Angew. Chem., Int. Ed. 48, $7540-7545$.

(41) Zomer-van Ommen, D. D., Pukin, A. V., Fu, O., Quarles van Ufford, L. H. C., Janssens, H. M., Beekman, J. M., and Pieters, R. J. (2016) Functional Characterization of Cholera Toxin Inhibitors Using Human Intestinal Organoids. J. Med. Chem. 59, 6968-6972.

(42) Amvam-Zollo, P.-H., and Sinaÿ, P. (1986) Streptococcus pneumoniae type XIV polysaccharide: synthesis of a repeating branched tetrasaccharide with dioxa-type spacer-arms. Carbohydr. Res. 150, 199-212.

(43) Heller, D. A., Levi, Y., Pelet, J. M., Doloff, J. C., Wallas, J., Pratt, G. W., Jiang, S., Sahay, G., Schroeder, A., Schroeder, J. E., Chyan, Y., Zurenko, C., Querbes, W., Manzano, M., Kohane, D. S., Langer, R., and Anderson, D. G. (2013) Modular "click-in-emulsion" bonetargeted nanogels. Adv. Mater. 25, 1449-1454.

(44) Pahimanolis, N., Vesterinen, A.-H., Rich, J., and Seppala, J. (2010) Modification of dextran using click-chemistry approach in aqueous media. Carbohydr. Polym. 82, 78-82.

(45) Dekkers, J. F., Wiegerinck, C. L., de Jonge, H. R., Bronsveld, I., Janssens, H. M., de Winter-de Groot, K. M., Brandsma, A. M., de Jong, N. W. M., Bijvelds, M. J. C., Scholte, B. J., et al. (2013) A functional CFTR assay using primary cystic fibrosis intestinal organoids. Nat. Med. 19, 939-945.

(46) Pukin, A. V., Branderhorst, H. M., Sisu, C., Weijers, C. C. A. G. M., Gilbert, M., Liskamp, R. M. J., Visser, G. M., Zuilhof, H., and Pieters, R. J. (2007) Strong inhibition of cholera toxin by multivalent GM1 derivatives. ChemBioChem 8, 1500-1503.

(47) De Bruyne, C. K., and Carchon, H. (1974) The acid hydrolysis of substituted phenyl alpha-D-galactopyranosides. Carbohydr. Res. 33, $117-125$.

(48) Liese, S., and Netz, R. R. (2018) Quantitative Prediction of Multivalent Ligand-Receptor Binding Affinities for Influenza, Cholera, and Anthrax Inhibition. ACS Nano 12, 4140-4147.

(49) Fu, O., Pukin, A. V., van Ufford, H. C. Q., Branson, T. R., Thies-Weesie, D. M. E., Turnbull, W. B., Visser, G. M., and Pieters, R J. (2015) Tetra- versus Pentavalent Inhibitors of Cholera Toxin. ChemistryOpen 4, 471-477.

(50) Sisu, C., Baron, A. J., Branderhorst, H. M., Connell, S. D., Weijers, C. C. A. G. M., de Vries, R., Hayes, E. D., Pukin, A. V., Gilbert, M., Pieters, R. J., Zuilhof, H., Visser, G. M., and Turnbull, W. B. (2009) The Influence of Ligand Valency on Aggregation Mechanisms for Inhibiting Bacterial Toxins. ChemBioChem 10, 329-337.

(51) Zhang, Z., Merritt, E. A., Ahn, M., Roach, C., Hou, Z., Verlinde, C. L. M. J., Hol, W. G. J., and Fan, E. (2002) Solution and crystallographic studies of branched multivalent ligands that inhibit the receptor-binding of cholera toxin. J. Am. Chem. Soc. 124, 1299112998.

(52) Mangan, D., and Snyder, I. S. (1978) The effect of acrylamide on human polymorphonuclear neutrophils in vitro. Occup. Environ. Med. 35, 305-311.

(53) Kim, W., Yang, Y., Kim, D., Jeong, S., Yoo, J. W., Yoon, J. H., and Jung, Y. (2017) Conjugation of metronidazole with dextran: A potential pharmaceutical strategy to control colonic distribution of the anti-amebic drug susceptible to metabolism by colonic microbes. Drug Des., Dev. Ther. 11, 419-429.

(54) Lauster, D., Glanz, M., Bardua, M., Ludwig, K., Hellmund, M., Hoffmann, U., Hamann, A., Böttcher, C., Haag, R., Hackenberger, C. 
P. R., and Herrmann, A. (2017) Multivalent Peptide-Nanoparticle Conjugates for Influenza-Virus Inhibition. Angew. Chem., Int. Ed. 56, $5931-5936$ 